\title{
Adaptation of the Physical Activity Neighborhood Environment Scale in Oman
}

Huda Al Siyabi, ${ }^{1}$ "Ruth Mabry, ${ }^{2}$ Mosa Al Subhi, ${ }^{3}$ Gustavo de Siqueira ${ }^{4}$

ABST RACT: Objectives: This study aimed to adapt the Physical Activity Neighborhood Environment Scale (PANES), which is a 17-item tool for assessing environmental factors relevant for walking and bicycling in the community, to the Omani context. Methods: The adaptation process was conducted in three steps: (1) revision by local experts, (2) Arabic translation and cognitive testing and (3) test-retest reliability testing with a sample of 33 Omani women and men, between September 2016 and August 2017. Results: Four of the 17 items of the PANES were modified and one was removed, resulting in a 16-item PANES, Oman (PANES-O) questionnaire. The test-retest reliability scores ranged from 0.436-1.000; scores for more than half $(\mathrm{n}=9)$ were almost perfect $(0.8-1.0)$, demonstrating a good level of consistency and good psychometric performance similar to other studies. Conclusion: The PANES-O demonstrated good test-retest reliability and appears to be a promising tool for assessing environmental perceptions related to physical activity in Oman. However, construct validity should be confirmed before wider use.

Keywords: Physical Activity; Built Environment; Exercise; Health Promotion; Policy; Transportation; Urban Planning; Oman.

$\mathrm{P}$ HYSICAL INACTIVITY IS ONE OF THE 10 LEADING risk factors for mortality; it causes 3.2 million deaths each year globally. ${ }^{1}$ The built environment of an area is associated with the physical activity levels of a population. Increased street connectivity, residential density and accessibility of mixed destinations are some of the environmental attributes that support physical activity. ${ }^{2-5}$ Research on the built environment's influence on physical activity in Oman and neighbouring countries is needed to guide public health policy. ${ }^{6}$ Reliable and valid measures of the built environment are available for conducting such research; however, they have not been tested for cities in the Arab world, including in the countries of the Arabian Peninsula. ${ }^{7-9}$

The Physical Activity Neighborhood Environment Scale (PANES), developed by the International Physical Activity Prevalence Study group, is a comprehensive yet brief measure of the perceived environment. This 17-item tool assesses adults' perceptions of the built environment's ability to support physical activity such as walking and bicycling in terms of land use mix, residential density, pedestrian infrastructure, aesthetic qualities and safety from traffic and crime. ${ }^{10}$ Studies that have used this tool have demonstrated associations of the built environment with physical activity in the lower, middle- and high-income countries on all five continents., ${ }^{9,11}$ The current study, the first in a two-part series, aimed to describe the adaptation of the PANES to the Omani context to assess the test-retest reliability of the Omani version.

\section{Methods}

The adaptation process followed a methodology similar to a previous study carried out in Nigeria. ${ }^{11}$ It was conducted in three phases between September 2016 and August 2017 in Oman: (1) revision by local experts in Muscat, (2) Arabic translation and cognitive testing in Muscat and (3) test-retest reliability testing with a sample of Omani women and men in Nizwa, a city $130 \mathrm{~km}$ from the capital city, Muscat.

The 17 items of the PANES tool measured the perceived attributes of the neighbourhood environment including residential density (1 item), access to destinations (3 items), paedestrian and bicycling facilities (4 items), recreational facilities (1 item), visual qualities (1 item), social environment (1 item), street connectivity (1 item), traffic safety (2 items), crime safety (2 items) and household motor vehicles (1 item). Perceptions were measured using a 4-point scale ranging from strongly disagree to strongly agree, except for two items. Response options for the residential density item ranged from singlefamily detached homes to apartments; the question about the number of vehicles was open-ended..$^{10}$

The tool was reviewed by seven experienced experts from a variety of backgrounds [Table 1]. The experts worked independently, and they were requested to propose replacements for items that were not relevant to the Omani environment. These replacements needed to be culturally appropriate equivalents. The experts suggested additional items 
Table 1: Characteristics of the local experts in Oman who reviewed the Physical Activity Neighborhood Environment Scale questionnaire

\begin{tabular}{|c|c|c|c|c|c|}
\hline No. & Gender & Workplace & Position at work & Education & $\begin{array}{c}\text { Work } \\
\text { experience } \\
\text { in years }\end{array}$ \\
\hline 2 & Male & College of Applied Science, Rustaq & $\begin{array}{c}\text { Assistant Professor of Physical } \\
\text { Activity }\end{array}$ & $\mathrm{PhD}$ & $\geq 20$ \\
\hline 3 & Male & Ministry of Housing, Muscat & Geographic & $\begin{array}{l}\text { Master's } \\
\text { Degree }\end{array}$ & 15 \\
\hline 4 & Male & Ministry of Environment, Muscat & $\begin{array}{c}\text { Director of Environmental } \\
\text { Affairs }\end{array}$ & $\begin{array}{l}\text { Bachelor's } \\
\text { Degree }\end{array}$ & $\geq 20$ \\
\hline 7 & Female & Petroleum Development Oman, Muscat & Dietician & $\begin{array}{l}\text { Master's } \\
\text { Degree }\end{array}$ & 15 \\
\hline
\end{tabular}

that were to be included if not already reflected. Feedback was provided to the research team on a separate form. The PANES questionnaire was revised based on the suggestions provided by the experts.

The revised English version, PANES Oman (PANES-O), was translated into the Arabic language by an Omani English language teacher and reviewed by the research team. Six public health experts were invited to a meeting to review the Arabic PANES-O. During the meeting participants were briefed about the background of the PANES including its development in Australia and the USA and its adaptation in Nigeria and Oman. ${ }^{9-11}$ The research team then facilitated a discussion about the clarity and relevance of each item including appropriate wording in the local Arabic dialect. Their suggestions for improvement were welcomed and items were rephrased as needed.

The test-retest reliability testing was carried out using a convenience sample of 50 women and men from different neighbourhoods and socioeconomic statuses (educational level and employment status) in Nizwa. Participants were approached directly to take part in the study from their home, college or place of work. Eligibility criteria included being between 18-60 years old, not having any disability and being willing to complete the survey in Arabic. Participants completed the questionnaire in the presence of a researcher twice, at a seven-day interval. Sociodemographic characteristics (age, gender, education and marital status) were included in the initial data collection. All participants provided informed consent.

Test-retest reliability was assessed using a oneway model single-measure intraclass correlation coefficient (ICC) to ascertain consistency across multiple observers along with a 95\% confidence interval. The test-retest reliability of each of the environmental variables was also conducted. Agreement ratings followed Landis and Koch's proposal, which was used in the Nigerian adaptation: poor $(0.0-0.2)$, fair (0.2-0.4), moderate (0.4-0.6), substantial (0.6-0.8) and almost perfect (0.8-1.0). ${ }^{11}$ The Statistical Package for the Social Sciences (SPSS), Version 16 (SPSS Inc., Chicago, Illinois, USA) was used for statistical analysis.

This study was designed and conducted in adherence to the requirements of the Declaration of Helsinki.

\section{Results}

Out of the 17 items of the PANES, four were modified and one was removed. The responses to item 1 ("What is the main type of housing in your neighbourhood?") were changed. Item 10 ("The crime rate in my neighborhood makes it unsafe to go on walks during the day") was changed to "Walking during the day is safe in my neighborhood, Item 11 ("The crime rate in my neighbourhood makes it unsafe to go on walks at night") was changed to "Walking at night is unsafe in my neighbourhood' and item 16 ("There are many four-way intersections in my neighbourhood") was modified to 'There are many cross-junctions in my neighborhood'. Item 17 ("How many motor vehicles in working orders [e.g. cars, trucks and motorcycles] are there at your household?") was deleted because of broad car ownership in the country [Table 2].

During the meeting with experts on the Arabic translation of PANES-O, the participants confirmed the clarity of the questions and their relevance to the 
Table 2: Adaptation of the Physical Activity Neighborhood Environment Scale questionnaire in Oman

\author{
Item \\ Original PANES question \\ no.
}

\section{Residential density}

1 What is the main type of housing in your neighbourhood?

$$
33.3
$$

\section{Access to destinations}

2 Many shops, stores, markets or other places to buy things I need are within easy walking distance from my home.

There are many places to go within easy walking distance from my home.

4 It is within a 10-15-minute walk to a transit stop (such as bus, taxi, train, trolley or tram) from my home.

\section{Neighbourhood infrastructure}

$5 \quad$ There are sidewalks on most of the streets in my neighbourhood.

6 There are facilities to bicycle in or near my neighbourhood, such as special lanes, separate paths or trails and shared-use paths for cycles and pedestrians.

$7 \quad$ Places for bicycling (such as bike paths) in and around my neighbourhood are well maintained and not obstructed.

8 My neighbourhood has several free or lowcost recreation facilities, such as parks, walking trails, bike paths, recreation centres playgrounds, and public swimming pools.

9 The sidewalks in my neighbourhood are well maintained (paved, with few cracks ) and not obstructed.

\section{Neighbourhood safety}

10 The crime rate in my neighbourhood makes it unsafe to go on walks during the day.

11 The crime rate in my neighbourhood makes it unsafe to go on walks at night.

12 There is so much traffic on the streets that it makes it difficult or unpleasant to walk in my neighbourhood.

13 There is so much traffic on the streets that it makes it difficult or unpleasant to ride a bicycle in my neighbourhood.

\section{Neighbourhood social environment}

14. I see many people being physically active in my neighbourhood and doing things like walking, jogging, cycling or playing sports and active games.

\section{Neighbourhood aesthetics}

15 There are many interesting things to look at while walking in my neighbourhood.

$\begin{array}{cccc}\text { Local expert's comments in \% } & \begin{array}{c}\text { Changes } \\ \text { made by } \\ \text { Relevant }\end{array} \text { Modify } & \begin{array}{c}\text { Not } \\ \text { relevant }\end{array} & \\ 66.6 & 33.3 & 0.0 & \begin{array}{c}\text { Options } \\ \text { rephrased }\end{array}\end{array}$

rephrased

What is the main type of housing in your neighbourhood? a.One-floor villa b.More than a one-floor villa c.More than a one-floor villa c.Apartment d.Detached single-family housing

Item rephrased

$$
\text { Item }
$$
rephrased rephrased rephrased

\section{Options} rephrased

\section{PANES-O item}

Many shops, stores, markets or other places to buy things I need are within easy walking distance from my home.

There are many places to go within easy walking distance from my home, such as mosques, schools, health institutions, workplaces, markets and parks.

It is within easy walking distance from my home to access the public transport and taxi in the main road of my neighbourhood.

There are sidewalks on most of the streets in my neighbourhood.

There are facilities to bicycle in or near my neighbourhood, such as special lanes, separate paths and shared-use paths for cycles and pedestrians.

Places for bicycling (such as bike paths) in and around my neighbourhood are well maintained and not obstructed.

My neighbourhood has several places such as open fields, parks, a sea, clubs and gymnasiums for exercising and playing football and other sports.

The sidewalks in my neighbourhood are well maintained (paved, with few cracks) and not obstructed.

Walking during the day is safe in my neighbourhood.

Walking at night is unsafe in my neighbourhood.

There is so much traffic on the streets that it makes it difficult or unpleasant to walk in my neighbourhood.

There is so much traffic on the streets that it makes it difficult or unpleasant to ride a bicycle in my neighbourhood.

I see many people being physically active in my neighbourhood and doing things like walking, jogging, cycling or playing sports and active games.
Appropriate
examples added
There are many interesting things to look at while walking in my neighbourhood, such as shady trees, building variety and a beautiful beach. 
Table 2 (cont'd): Adaptation of the Physical Activity Neighborhood Environment Scale questionnaire in Oman

$\begin{array}{lllll}\begin{array}{l}\text { Item } \\ \text { no. }\end{array} & \text { Original PANES question } & \text { Local expert's comments in \% } & \text { Changes } & \text { PANES-O item } \\ \text { made by } & \text { Relevant } & \text { Modify } & \begin{array}{c}\text { Not } \\ \text { relevant }\end{array} & \text { experts }\end{array}$

\section{Street connectivity}

16 There are many four-way intersections in my neighbourhood.

\section{Motor vehicle}

$17 \quad$ How many motor vehicles in working orders (e.g. cars, trucks and motorcycles) are there at your household?
57.

28.5

100.0

0.0
14.2

0.0

Item
rephrased

There are many cross-junctions in my neighbourhood. (n) How many motor vehicles in working orders (e.g
cars, trucks and motorcycles) are there at your household?

country except for item 1 . For item 1 ("What is the main type of housing in your neighbourhood?"), the housing options were changed. Although participants were concerned about the applicability of the items about neighbourhood infrastructure (such as sidewalks and bicycle pathways), they agreed to retain these items.

A total of 33 participants (response rate: 66\%), with a mean age of $35.9 \pm 10.2$ years, completed the test-retest reliability survey. A majority were married (78.8\%), two-thirds of the participants were women (66.7\%) and the same percentage had at least a high school education.

The results of the test-retest reliability were good overall with ICC scores ranging from 0.436-1.000. Of the 16 items, nine had an almost perfect agreement (ICC $=0.8-1.0$ ) with one item on the neighbourhood infrastructure ("There are facilities to bicycle in or near my neighbourhood, such as special lanes, separate paths and shared-use paths for cycles and pedestrians") having a perfect score (ICC $=1.0$ ) Of the remaining seven items, five showed substantial agreement (ICC $=0.6-0.8)$, and two items that were related to the neighbourhood social environment and aesthetics showed moderate agreement $(\mathrm{ICC}=0.4-0.6)$. For four items, a substantial proportion $(25-50 \%)$ of the participants reported that they did not know and/or the item was not applicable; three were related to the neighbourhood infrastructure and one was related to the neighbourhood social environment [Table 3].

\section{Discussion}

The adaptation of the PANES instrument to the Omani context showed promise in terms of assessing perceptions about the built environment in Oman. A high portion of non-responses to items related to the neighbourhood infrastructure and social environment possibly reflected the development patterns and cultural context of Oman and the city of Nizwa in particular.
Oman has developed rapidly in the past 50 years following a Western planning model of functional spatial segregation and dispersal of low-density settlements. ${ }^{12,13}$ Newer communities are not designed to be supportive of walking and cycling. ${ }^{14}$ Although older parts of Nizwa follow traditional designs that may be more supportive of active travel, like Muscat, the challenges respondents faced in completing certain items may have reflected their experience in the newer neighbourhoods. In addition, cultural perceptions have altered people's attitudes towards walking and bicycling, especially among the younger population. ${ }^{12-16}$

The test-retest reliability scores ranged from 0.436-1.000 and scores for more than half of the items were almost perfect $(0.8-1.0)$, demonstrating a good level of consistency and good psychometric performance similar to those reported in other studies. ${ }^{10,11}$ All items assessing residential density, access to destinations, neighbourhood safety and street connectivity had higher reliability coefficients ( $>0.650$ ) compared to items on social environment and aesthetics. Neighbourhood social environment, the item with the lowest score, was also the item that the largest number of participants did not respond to; this may have reflected both the negative socio-cultural perceptions towards active travel and an unsupportive built environment. ${ }^{6,13-15}$ Further research is needed to confirm retention and possible rewording of items that scored poorly or received a limited response.

The main strength of this study was the systematic adaptation of this internationally validated tool. However, the modest non-representative sample size from one city limited its generalisability despite the demographic diversity of the sample in terms of age, gender and educational level. Selecting samples from a variety of neighbourhood environments would help in better measuring the variability in perceptions about the built environment and confirming the utility of this tool in the Omani context. ${ }^{10}$ 
Table 3: Intraclass correlation coefficients of the test-retest reliability of the adapted Physical Activity Neighborhood Environment Scale, Oman ( $=33)$

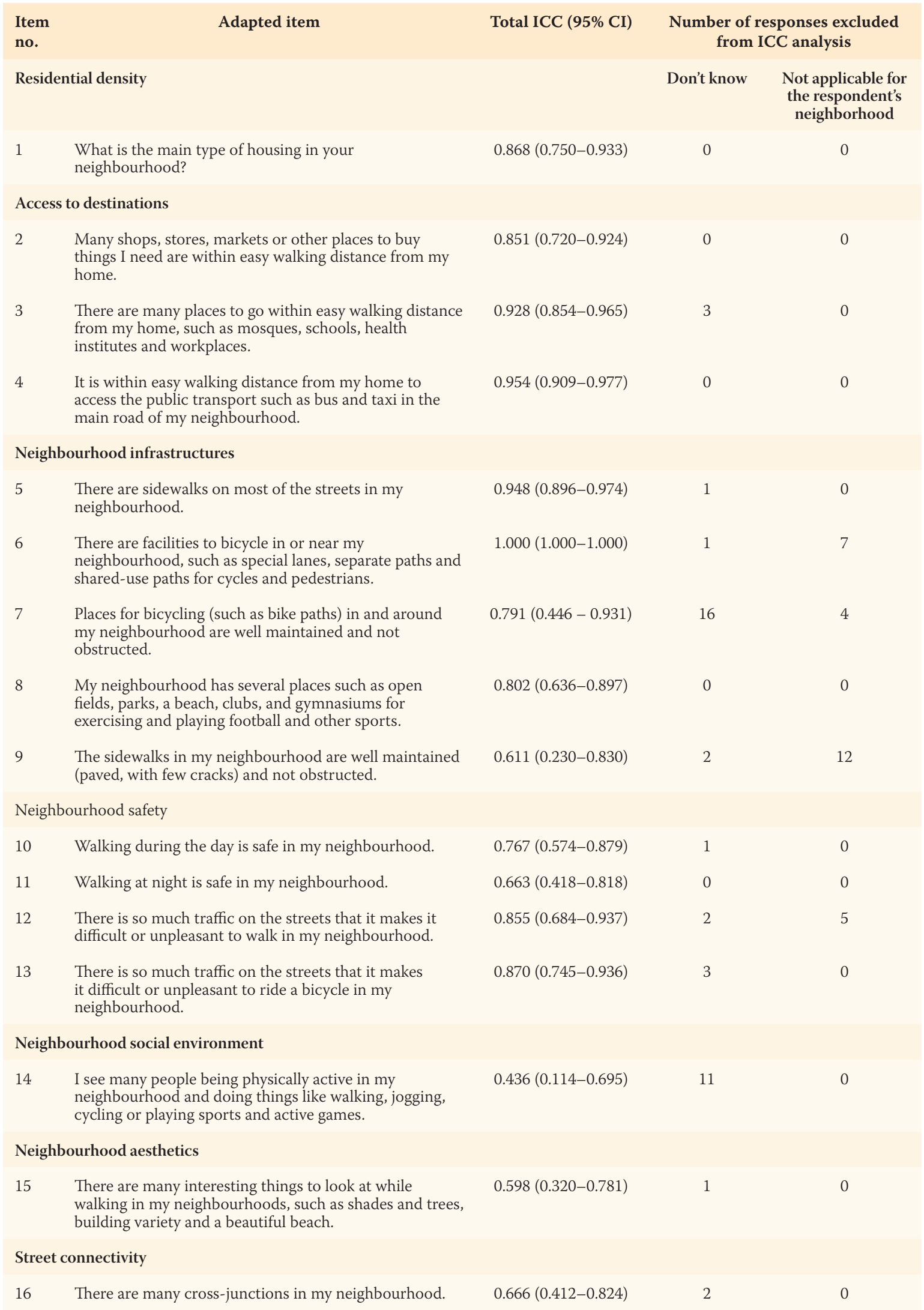

$I C C=$ intraclass correlation coefficient; $C I=$ confidence interval 


\section{Conclusion}

This study supported theview that PANES is a promising measure of perceptions of the built environment related to physical activity. Specifically, the PANES-O demonstrated good test-retest reliability. Phase two of this study will examine the construct validity of this tool. Further research to confirm these findings using objective measures and respondents from a variety of neighbourhoods is needed before wider use.

\section{ACKNOWLEDGEMENTS}

The authors acknowledge the support of national experts who reviewed the PANES and the participants who field-tested the tool. The views expressed in this paper are those of the authors and do not necessarily reflect those of the World Health Organization.

\section{CONFLICT OF INTEREST}

The authors declare no conflicts of interest.

\section{FUNDING}

No funding was received for this study.

\section{AUTHORS' CONTRIBUTION}

HA and RM conceived the study and planned the project. HA and MA carried out the field work and data analysis. RM took the lead in preparing the manuscript. All authors provided critical feedback and approved the final version of the manuscript.

\section{Reference}

1. World Health Organization. Global Status Report on noncommunicable diseases 2014. Geneva: World Health Organization, 2014.

2. Sallis JF, Floyd MF, Rodríguez DA, Saelens BE. Role of built environments in physical activity, obesity, and cardiovascular disease. Circulation 2012; 125:729-37. https://doi.org/10.1161/ CIRCULATIONAHA.110.969022.

3. Ding D, Gebel K. Built environment, physical activity, and obesity: What have we learned from reviewing the literature? Health Place 2012; 18:100-5. https://doi.org/10.1016/j. healthplace.2011.08.021.

4. Durand CP, Andalib M, Dunton GF, Wolch J, Pentz MA. A systematic review of built environment factors related to physical activity and obesity risk: Implications for smart growth urban planning. Obes Rev 2011; 12:e173-82. https://doi. org/10.1111/j.1467-789X.2010.00826.x.
5. Gul Y, Sultan Z, Johar F. Effects of neighborhood's built environment on physical activities in gated communities: A review. International Journal of Built Environment and Sustainability 2016; 3. https://doi.org/10.11113/ijbes.v3.n1.112.

6. Mabry R, Koohsari MJ, Bull F, Owen N. A systematic review of physical activity and sedentary behaviour research in the oil-producing countries of the Arabian Peninsula. BMC Public Health 2016; 16:1003. https://doi.org/10.1186/s12889-016-3642-4.

7. Brownson RC, Hoehner CM, Day K, Forsyth A, Sallis JF. Measuring the built environment for physical activity: State of the science. Am J Prev Med 2009; 36:S99-123.e12. https://doi. org/10.1016/j.amepre.2009.01.005.

8. Cerin E, Conway TL, Cain KL, Kerr J, De Bourdeaudhuij I, Owen N, et al. Sharing good NEWS across the world: Developing comparable scores across 12 countries for the Neighborhood Environment Walkability Scale (NEWS). BMC Public Health 2013; 13:309. https://doi.org/10.1186/1471-2458-13-309.

9. Ding D, Adams MA, Sallis JF, Norman GJ, Hovell MF, Chambers $C D$, et al. Perceived neighborhood environment and physical activity in 11 countries: Do associations differ by country? Int J Behav Nutr Phys Act 2013; 10:57. https://doi. org/10.1186/1479-5868-10-57.

10. Sallis JF, Kerr J, Carlson JA, Norman GJ, Saelens BE, Durant N, et al. Evaluating a brief self-report measure of neighborhood environments for physical activity research and surveillance: Physical activity neighborhood environment scale (PANES). J Phys Act Health 2010; 7:533-40. https://doi.org/10.1123/ jpah.7.4.533.

11. Oyeyemi AL, Sallis JF, Oyeyemi AY, Amin MM, De Bourdeaudhuij I, Deforche B. Adaptation, test-retest reliability, and construct validity of the Physical Activity Neighborhood Environment Scale in Nigeria (PANES-N). J Phys Act Health 2013; 10:1079-90. https://doi.org/10.1123/jpah.10.8.1079.

12. Al-Gharibi H. Urban Growth in Muscat from Patchwork to Sustainability. Ph.D. Thesis, 2014, Technical University, Berlin, Germany.

13. Nebel S, von Richthofen, Eds. Urban Oman, Trends and Perspectives of Urbanisation in Muscat Capital Area. Zurich, Switzerland: LIT Verlag, 2016.

14. Jafari M, Scholz W. Towards Sustainable urban development: Challenges and chances of climate-sensitive urban design in Muscat/Oman. In: Azar E, Raouf MA, Eds. Sustainability in the Gulf: Challenges and Opportunities. London, UK: Routledge, 2018. Pp. 103-122.

15. Mabry RM, Al Siyabi H, Kannan M, Al Siyabi A. Physical activity and the built environment: Perceptions of policymakers in Oman. Health Promot Int 2020: 35;762-70. https:// doi.org/10.1093/heapro/daz066

16. Mabry RM, Winkler EA, Reeves MM, Eakin EG, Owen N. Correlates of Omani adults' physical inactivity and sitting time. Public Health Nutr 2013; 16:65-72. https://doi.org/10.1017/ S1368980012002844. 